\title{
A Systematic Mapping Study on Requirements Elicitation Techniques in Collaborative Application
}

\author{
Noorihan Abdul Rahman and Shamsul Sahibuddin
}

\begin{abstract}
This paper describes a mapping study to identify what are the existing requirements elicitation available for Computer-Supported Collaboration Work (CSCW) application. This study also points out type of requirements which the developers look for during requirements elicitation. Based on 14 papers that have been refined from the study, the authors look at types of domain involved in CSCW application. This paper also describes potential requirement to support social presence in collaborative application such as in Elearning as one of the domain in CSCW application.
\end{abstract}

Index Terms-User, requirements elicitation, interaction, CSCW, social presence, e-learning, collaboration.

\section{INTRODUCTION}

Effective collaborative application is very essential to drive users to learn and use the system actively as in online community. In developing E-learning as a collaborative application, requirements engineers should gather the requirements needed by users to ensure that they can interact and share knowledge actively in E-learning community. This paper produces a mapping study to see existing requirements elicitation process for various domains in CSCW. In addition, the study also reveals the requirements that developers usually look for in creating CSCW application, whereby it is usable for human-human interaction using CSCW application.

The objective of this work has been achieved through a systematic literature review (SLR), following the approach of Kitchenham et al.[1] . According to Kitchenham et al., SLR is a research technique to analyze the state-of-the-art in a particular field of knowledge by formally defining the problem statement, the sources of information, the search strings, the criteria for inclusion and exclusion of the papers found in the searches, the quantitative analysis to be undertaken if necessary and the templates for ordering the information collected from the papers. To initiate SLR, authors need to carry out the search process based on Research Questions (RQ), which will be revealed in Section II. RQ is useful as the guidance for the authors to identify their keywords and limitation for systematic literature

Manuscript received September 19, 2012; revised November 14, 2012. This work was supported by the Universiti Teknologi Malaysia, managed by Research Management Centre (RMC), UTM with vote number 02H40 under Research University Grant (RUG).

N. A., Rahman is with the Universiti Teknologi Malaysia, and the Faculty of Computer Science and Mathematics, Universiti Teknologi MARA Kelantan, Bukit Ilmu,18500 Machang, Kelantan. Malaysia (e-mail: noorihan@kelantan.uitm.edu.my).

S. Shamsul is with the Advanced Informatics School, Universiti Teknologi Malaysia, Kuala Lumpur, 54100 Wilayah Persekutuan, Malaysia (e-mail: shamsul@utm.my). survey.

\section{Systematic MaPPing Plan}

Broad search with some keywords have been used in finding related literature for the research. The papers are gathered based on some criteria of keywords during search process of SLR.

\section{A. The Research Questions}

This paper addresses two research questions related with the study. The first research question has helped the researchers to narrow down topic or issue that needs to be searched for. The first question, 'What are existing requirements elicitation processes for E-learning or other Computer-Supported Collaborative Work (CSCW) applications?' is equivalent to the original study.

The second research question is also taken from the original study. This research question is going through SLR process to see requirements that have been identified during existing requirements elicitation. The question is, "What are the type of requirements involved for supporting collaboration in E-learning or CSCW application for stakeholders?'

\section{B. The Search Process}

The search process involved Scopus Indexing System. The search took place between 2007 to recent and based on keywords from the paper. The authors have decided to include 5 keyword strings which consist of possible terms which may relate to systematic review objective. The search strings are as follows:-

1) "Requirements technique" and "requirements engineering" and "CSCW".

2) "Requirements elicitation" and "requirements engineering" and "CSCW".

3) "Requirements gathering" and "requirements engineering" and "CSCW".

4) "Requirements model" and "requirements engineering" and "CSCW".

5) "Requirements process" and "requirements engineering" and "CSCW".

\section{Study Selection}

In acquiring data and assessing the quality of the reviews, authors have identified two objectives according to the research questions. The first objective is to indentify papers that pointed out what is the requirements elicitation process that have been used in collaborative application. The second objective is to discover what requirements that they concern during requirements gathering. There is no specific protocol that has been established in order to do quality assessment. 
In producing the result, authors have selected publications which came from conference proceedings as well as from journal papers. There are some criteria of inclusion and exclusion from the results of paper which have been based on keyword strings earlier on.

\section{Inclusion Criteria}

The authors include studies which are related to requirements engineering area and Computer-Supported Collaborative Work (CSCW). The mapping studies also take into account empirical studies for identifying what is the existing requirements elicitation available for respective domain. The studies also try to spot type of requirements involved in $\mathrm{CSCW}$ application regardless from several domains selected. The studies are selected from journals and conference papers.

\section{E. Exclusion Criteria}

However, those studies exclude some criteria in the review protocol. It does not include concept papers, workshop papers, papers that are not related with information technology disciplines. There are papers that have been rejected during refinement process since the content is not related with the research questions for this study.

\section{RESULT}

The mapping study is done to see the example of existing elicitation that is related to possible requirements that they have gathered. Table I reveals existing studies on requirements elicitation from various domains from 2008 until recent.

\section{ApPlicAtion OF REVIEW Protocol}

The application of the review protocol produced as specified 14 publications consists of conference papers and journal papers. The 14 papers have been refined from 28 of papers. During the selection process, the authors have identified that there are a few identical papers resulted from different keyword strings. Most of the papers are selected from empirical studies and they may be published in the form of papers or journals simultaneously.

\section{DISCUSSION}

This paper provides some discussion from the variety of domains in CSCW and the requirements type that authors are interested for their research.

\section{A. Domain}

There are 7 categories of domains from the studies. Among 14 refined papers that have been selected based on inclusion and exclusion criteria. Table II stated number of papers for each domain for selected studies.

\section{B. Requirements Elicitation Technique}

From the mapping study, the authors have found out that researchers use different kinds of elicitation technique to gain type of requirements that they want to extract from the domain, however, their goals is the same which is to improve user interaction and collaboration in using CSCW application. Storytelling has been used as the technique to elicit requirements and to transform the requirements into technical representation which the developer is able to understand[16]. Two papers use psychological approach to obtain requirements from users. The two approaches have been identified as Activity Theory and small group theory respectively[11]-[16] whereby 2 papers have mentioned prototype as the way to get the requirements from their domain[9],[11],[15]-[16].

\begin{tabular}{lc}
\multicolumn{1}{c}{ Domain } & $\begin{array}{c}\text { No of } \\
\text { Paper }(\boldsymbol{s})\end{array}$ \\
\hline \hline Ubiquitous computing & 2 \\
E-learning & 2 \\
Enterprise Resource Planning & 1 \\
Online service for disabilities & 1 \\
Socio-technical system & 1 \\
$\begin{array}{l}\text { Medical/Health information } \\
\text { systems }\end{array}$ & 3 \\
CSCW-related system & 5 \\
\hline \hline
\end{tabular}

Regardless of various elicitation techniques, a traditional technique such as interview[5]-[7] is still being implemented in order to gain requirements from user and there is also a participatory approach from expert as well as users[13]-[14] in CSCW development.

\section{Type of Requirements in Existing CSCW}

From 28 papers, there is only 14 papers stated clearly types of requirements that authors have interest at. Table III shows type of requirements in CSCW application.

TABLE III: TYPE OF REQUIREMENTS IN SELECTED STUDIES.

\begin{tabular}{|c|c|}
\hline Reference & Requirement Type \\
\hline \multirow{4}{*}[2]{} & Improve requirements from team using \\
\hline & Activity Theory. \\
\hline & Help willingness \\
\hline & Initial availability \\
\hline \multirow[t]{3}{*}[3]{} & Preferences \\
\hline & Student knowledge level \\
\hline & Potential helper as an agent \\
\hline [4] & $\begin{array}{l}\text { Requirements for ubiquitous E-learning } \\
\text { system. }\end{array}$ \\
\hline$[5]$ & Requirements for disabilities. \\
\hline$[6]$ & Requirements for collaboration projects. \\
\hline [7] & Requirements for 4D collaboration tools. \\
\hline [8] & $\begin{array}{l}\text { Requirements for cooperative task in } \\
\text { multi-group environment. }\end{array}$ \\
\hline [9] & $\begin{array}{l}\text { Requirements for multi modal } \\
\text { interaction. }\end{array}$ \\
\hline$[10]$ & $\begin{array}{l}\text { Requirements to improve human } \\
\text { interaction using collaborative theory. }\end{array}$ \\
\hline$[11]$ & Social computing requirements. \\
\hline$[12]$ & Requirements for collaborative product. \\
\hline$[13]$ & Requirements for elderly homecare. \\
\hline [14] & $\begin{array}{l}\text { Requirements to integrate users in } \\
\text { medical devices. }\end{array}$ \\
\hline$[15]$ & $\begin{array}{l}\text { Requirements for data integration, } \\
\text { analysis services, communication } \\
\text { mechanisms. }\end{array}$ \\
\hline
\end{tabular}




\section{Possible Requirements for Collaboration Activities}

TABLE I: EXISTING STUDIES ON REQUIREMENT ELICITATION

\begin{tabular}{|c|c|c|c|c|}
\hline Reference & Paper Type & Objective & $\begin{array}{c}\text { Elicitation } \\
\text { Component }\end{array}$ & Domain \\
\hline$[2]$ & Conference paper & $\begin{array}{l}\text { To support interaction between } \\
\text { user and analyst and to convert } \\
\text { the stories into a technical } \\
\text { representation. }\end{array}$ & $\begin{array}{l}\text { Storytelling, Activity } \\
\text { Theory, use case } \\
\text { construction. }\end{array}$ & CSCW \\
\hline [3] & Conference paper & $\begin{array}{l}\text { To improve collaboration } \\
\text { between users in E-learning } \\
\text { environment. }\end{array}$ & $\begin{array}{l}\text { Intelligent system, e- } \\
\text { assistant- to ensure E- } \\
\text { learning is running } \\
\text { dynamically between } \\
\text { users. }\end{array}$ & E-learning \\
\hline [4] & Conference paper & $\begin{array}{l}\text { To gather information from } \\
\text { users' input using scenario. }\end{array}$ & $\begin{array}{l}\text { Distributed scenario } \\
\text { based method. }\end{array}$ & $\begin{array}{l}\text { Ubiquitous E-learning } \\
\text { platform }\end{array}$ \\
\hline$[5]$ & Conference paper & $\begin{array}{l}\text { To elicit information from } \\
\text { various stakeholders including } \\
\text { people with disabilities }\end{array}$ & $\begin{array}{l}\text { Online surveys, } \\
\text { interviews, focus } \\
\text { group schedules, } \\
\text { online mailing lists, } \\
\text { review of existing } \\
\text { literature }\end{array}$ & $\begin{array}{l}\text { online } \\
\text { services in education } \\
\text { environments for people } \\
\text { with disabilities }\end{array}$ \\
\hline$[6]$ & Conference paper & $\begin{array}{l}\text { To model users' views in } \\
\text { collaborative projects }\end{array}$ & Interviews & $\begin{array}{l}\text { Groupware oriented } \\
\text { system for construction } \\
\text { project }\end{array}$ \\
\hline [7] & Conference paper & $\begin{array}{l}\text { To model users' views for 4D } \\
\text { collaboration tools }\end{array}$ & $\begin{array}{l}\text { Visualization task } \\
\text { model }\end{array}$ & $\begin{array}{l}\text { Architecture, engineering, } \\
\text { construction (AEC) }\end{array}$ \\
\hline$[8]$ & Conference paper & $\begin{array}{l}\text { To support cooperative works } \\
\text { that involve multiple groups }\end{array}$ & $\begin{array}{l}\text { Multi-group } \\
\text { cooperative } \\
\text { organization-activity } \\
\text { model }\end{array}$ & CSCW \\
\hline [9] & Conference paper & $\begin{array}{l}\text { To support human collaboration } \\
\text { in context-aware systems, } \\
\text { support data centered } \\
\text { requirement }\end{array}$ & Simulation, prototype & Ubiquitous computing \\
\hline$[10]$ & $\begin{array}{l}\text { Conference paper } \\
\text { Journal paper }\end{array}$ & $\begin{array}{l}\text { To improve ERP my improving } \\
\text { user-system collaboration }\end{array}$ & $\begin{array}{l}\text { Cognitive } \\
\text { walkthrough -the } \\
\text { answer from the } \\
\text { questions is taken as } \\
\text { the basis for } \\
\text { predicting users' } \\
\text { success or failure to } \\
\text { properly complete the } \\
\text { task. }\end{array}$ & ERP \\
\hline [11] & Conference paper & $\begin{array}{l}\text { Propose a set of generic } \\
\text { requirements or analysis issues } \\
\text { that } \\
\text { need to be addressed when } \\
\text { specifying technical system } \\
\text { from psychology view. }\end{array}$ & $\begin{array}{l}\text { Use socio } \\
\text { psychological } \\
\text { Theory to analyze }\end{array}$ & Socio-technical systems \\
\hline$[12]$ & Conference paper & $\begin{array}{l}\text { To support dynamic nature of } \\
\text { collaborative design }\end{array}$ & $\begin{array}{l}\text { Feature-based product } \\
\text { data model }\end{array}$ & CSCW \\
\hline [13] & Journal paper & $\begin{array}{l}\text { To bring the experts to } \\
\text { understand the same issue and } \\
\text { achieve the same goal. }\end{array}$ & $\begin{array}{l}\text { Participatory design } \\
\text { using multi- } \\
\text { disciplinary thematic } \\
\text { seminar from user } \\
\text { experts. }\end{array}$ & $\begin{array}{l}\text { Health information } \\
\text { systems }\end{array}$ \\
\hline$[14]$ & Conference paper & $\begin{array}{l}\text { To elicit in participatory design } \\
\text { for users }\end{array}$ & Participatory research & $\begin{array}{c}\text { medical device } \\
\text { development }(M D D)\end{array}$ \\
\hline$[15]$ & Conference paper & $\begin{array}{l}\text { To come out with a conceptual } \\
\text { model for CSCW system }\end{array}$ & Prototype & Medical \\
\hline
\end{tabular}

From selected studies, the authors have identified that all CSCW application have emphasized on collaborative activities among user in order to improve user interaction. Therefore, this section is to give some preview regarding possible requirements that involved in collaborative activities. This section gives preview according to Elearning domain as one of CSCW application.

Collaborative involves a group of people working together to attain goal[17]. According to Alonso et al.[18], there are importance in collaboration whereby it enables people to learn mutually and participate actively to do tasks. According to Shulman[19], 'the active, collaborative, reflective re-examination of ideas in a social context is one of the most important remedies for combating the illusion of misunderstanding and persistence of misconceptions'. Collaboration needs support from effective groupware application for encouraging users to access online environment. In order to have effective groupware, developer should identify what are the factors that may lead to successful online communities. In developing an application or software that has the capability to support collaborative activities among user, developers need to obtain a set of requirements which has the element of supporting collaborative activities for users.

Collaborative activities in e-learning allow learners to communicate for knowledge sharing during learning process 
regardless of ways of interaction in E-learning platform. Learners can perform activities like discussion, online quiz and assignment, announcement in online forum, chatting with friends and other related tasks which can help them to share their knowledge and ideas. However, there is a challenge in sustaining learning interest in E-learning. Some students lack of motivation to interact and feel insecure to expose their opinions in E-learning. There is also an issue in preserving the usability of E-learning among students and hence reduce the flexibility to learn anytime anywhere. Having said that, we believe that there is an opportunity in enhancing the knowledge of requirements elicitation for collaborative application especially for E-learning domain. This is due to the fact that developers and other stakeholders need to be aware on how to plan and design the right application in order to sustain collaboration among learners. Requirements engineers also take part in discovering the right requirements that can maintain collaboration and therefore improve requirements elicitation for developers by preparing accurate requirements specification document for sustaining social interaction among learners. The element of interaction needs to be studied further by the requirements engineer in order to come out with an accurate set of requirements. Table IV reveals examples of element on interaction in Computer-Supported Collaborative Work (CSCW) application.

Social factors in software development can be considered as the requirement to permit interaction between users and the application whenever the system is being use. Social factors are factors that can be studied in order to raise social interaction in CSCW application. In E-learning, for instance, users interact by sharing knowledge on certain topics, according to their preferences. The interaction among users is also motivated by active collaboration since they feel comfortable and created social bonding virtually. By having comfort and sufficient bonding among themselves, it also affects users' emotion in learning. As the result, effective learning process is achieved even though it is online. Table IV depicts social factors in the context of software development. Those factors are the possible factors in CSCW application whenever users interact among themselves. In this paper, the authors relate social presence with possible factors of social interaction by identifying how social presence exists in E-learning during learning process. Subsection E elucidates social presence definition and its role in E-learning application.

\begin{tabular}{ll}
\multicolumn{1}{c}{ TABLE IV: FACTORS OF SOCIAL INTERACTION IN CSCW } \\
\hline CSCW \\
Knowledge sharing & \multicolumn{1}{c}{ References } \\
Personal preferences & {$[20-23]$} \\
Customer/User collaboration & {$[24]$} \\
& {$[25,20,22,26-$} \\
Motivation & $28]$ \\
Social bonding /social interaction & {$[25,22,29]$} \\
& {$[30,29,31,32$,} \\
\hline \hline
\end{tabular}

\section{E. Social presence as the Social Interaction Element}

This section converses definition of social presence and its role in E-learning domain. The theory of social presence is important since social presence technology is hoped to be an alternative to face to face interaction among individuals[33]. The theory is also related to mediatedinteraction technology which particularly explained different technological forms that can assist social interaction which encourage mind interaction among users. Table $\mathrm{V}$ summarizes the definition of social presence for clearer description on social presence.

Social interaction in E-learning is an activity among users in order to achieve effective learning process. It happens during online discussion or interaction regarding E-learning contents. In developing E-learning, developers need to comprehend what is the element of social presence as to support social interaction among E-learning users. Therefore, the authors suggest that it is important for requirements engineer to carry out with requirements elicitation technique which can help to transform element of social interaction into meaningful information for requirement specification.

TABLE V: DEFINITION OF SOCIAL PRESENCE

\begin{tabular}{l}
\hline \multicolumn{1}{c}{ Definition of Social Presence } \\
\hline "the degree of awareness of another person in an \\
interaction and the consequent appreciation of an \\
interpersonal" \\
sense of "being with others" \\
A quality inherent in a communication medium \\
"the extent to which a medium allows users to \\
experience others as being psychologically present \\
"the degree to which participants in computer- \\
mediated communication feel affectively \\
connected one to another, has been shown to be an \\
important factor in student satisfaction and success \\
in online courses" \\
Social presence is divided into three concepts \\
which are co-presence, mutual awareness and \\
connectedness. Social presence as co-presence is \\
the feeling of collaborating with other person as if \\
they are in the same location, space or room. \\
Whereas, social presence as mutual awareness can \\
be considered as the feeling of others' existence in \\
a mediated environment and connectedness \\
revealed the meaning of having social exchanges \\
and to be acquainted among each other. \\
\hline \hline
\end{tabular}

\section{CONCLUSION}

Collaboration plays a major role in collaborative application $[25,39,40,21,30,31,41]$. In collaborative application such as E-learning, users need to experience effective collaboration and knowledge sharing in order to achieve learning process. The authors believe that social interaction is the important element to promote effective learning process. This can be done by ensuring that the feeling of connectedness and awareness live whenever learners or users use E-learning application. The feeling can be categorized as social presence in online application and in this case, requirements elicitation technique can support the implementation by preparing accurate requirements documents which has the social presence element for encourage social interaction in E-learning.

Requirements elicitation technique plays essential part in preparing a set of requirements which may cater human activity such as social presence in E-learning. Our future work will focus on how to elicit requirements based on social presence in collaborative application. Proposed requirements elicitation technique will also help 
requirements engineer and developer to extract social presence in a preferable and understandable way for developers. The selected domain, E-learning, will be the case study to identify collaborative activities that involved with human activities in E-learning. From human activities, the authors plan to propose and accommodate suitable requirements elicitation technique to support social presence in the interaction. The authors believe that the proposed technique may contribute in enhancement for knowledge of requirements elicitation technique by supporting requirements that consists of social presence element for improving social interaction in CSCW.

\section{ACKNOWLEDGEMENT}

The work reported herein was fully supported by the Research University Grant (RUG), Universiti Teknologi (UTM), Malaysia, under Vote Number 02H40. The authors would also like to thank Ministry of Higher Education (MOHE), Malaysia and Universiti Teknologi MARA (UiTM), Malaysia for supporting the research.

\section{REFERENCES}

[1] B. Kitchenham and S. Charters, "Guidelines for performing systematic literature reviews in software engineering," Engineering, 2007, vol. 2.

[2] V. Laporti, M. R. S. Borges, and V. P. Braganholo, "A collaborative approach to requirements elicitation," IEEE, 2007.

[3] C. Huafeng et al. "Text-based requirements preprocessing using nature language processing techniques," presented at 2010 International Conference on Computer Design and Applications

[4] A. Zuccato, V. Endersz, and N. Daniels, "Security Requirement Engineering at a Telecom Provider," presented at Third International Conference on Availability, Reliability and Security, 2008.

[5] T. Riechert and T. Berger, "Leveraging semantic data Wikis for distributed requirements elicitation," presented at ICSE Workshop on Wikis for Software Engineering, 2009.

[6] E. Knauss and D. Lubke, "Using the Friction between Business Processes and Use Cases in SOA Requirements," presented at 32nd Annual IEEE International on Computer Software and Applications, 2008.

[7] D. Ameller, X. Franch, and J. Cabot, "Dealing with Non-Functional Requirements in Model-Driven Development," presented at 2010 18th IEEE International on Requirements Engineering Conference.

[8] H. M. Kienle and H. A. Muller, "Requirements of Software Visualization Tools: A Literature Survey," presented at 4th IEEE International Workshop on Visualizing Software for Understanding and Analysis, 2007.

[9] E. I. Neaga and M. J. de C Henshaw, "Modeling the linkage between systems interoperability and security engineering," presented at 5th International Conference on System of Systems Engineering, 2010.

[10] M. A. A. Babar, "Framework for Supporting the Software Architecture Evaluation Process in Global Software Development," presented at Fourth IEEE International Conference on Global Software Engineering, 2009.

[11] I. Erfurth and K. Kirchner, "Requirements Elicitation with Adapted CUTA Cards: First Experiences with Business Process Analysis," presented at 15th IEEE International Conference on Engineering of Complex Computer Systems, 2010.

[12] M. J. Monasor et al. "Preparing Students and Engineers for Global Software Development: A Systematic Review," presented at 5th IEEE International Conference on Global Software Engineering, 2010.

[13] P. G. Sapna and A. Balakrishnan, "Using Ontologies to Aid the Teaching of Software Engineering," presented at 22nd Conference on Software Engineering Education and Training, 2009.

[14] O. M. Bonilla, X. Franch, and C. Quer, "Requirements Patterns for COTS Systems," presented at Seventh International Conference on Composition-Based Software Systems, 2008.

[15] P. Lago, J. Schalken, and H. V. Vliet, "Designing a Multi-disciplinary Software Engineering Project," presented at 22nd Conference on Software Engineering Education and Training, 2009.
[16] T. Schaaf and M. Brenner, "On tool support for Service Level Management: From requirements to system specifications," presented at 3rd IEEE/IFIP International Workshop on Business-driven IT Management, 2008.

[17] T. Bentley, L. Johnston, and K. V. Baggo, Putting some emotion into requirements engineering, 2002: Citeseer.

[18] F. Alonso et al., "An instructional model for web-based e-learning education with a blended learning process approach," British Journal of Educational Technology, 2005, vol. 36, no. 2, pp. 217-235.

[19] L. S. Shulman, "Taking Learning Seriously," Change Magazine, 1999, pp. 10-17.

[20] C. Dalsgaard, "Social software: E-learning beyond learning management systems," European Journal of Open, Distance and ELearning, vol. 2, 2006.

[21] J. Hou, C. Su, and W. Wang, Knowledge management in collaborative design, 2008

[22] A. Law and R. Charron, Effects of agile practices on social factors, 2005: ACM

[23] S. Masterton and S. Watt, "Oracles, bards, and village gossips, or social roles and meta knowledge management," Information Systems Frontiers, 2000, vol. 2, no. 3, pp. 299-315.

[24] G. N. Aranda, et al., "A Cognitive Perspective for Choosing Groupware Tools and Elicitation Techniques in Virtual Team," Computational Science and Its Applications-ICCSA 2005, pp. 10641074 .

[25] R. M. Bernard, B. R. de Rubalcava, and D. St-Pierre, "Collaborative online distance learning: Issues for future practice and research," Distance Education, 2000, vol. 21, no. 2, pp. 260-277.

[26] F. Safayeni et al., "Requirements engineering in new product development," Communications of the ACM, 2008, vol. 51, no. 3, pp 77-82.

[27] F. M. Santoro, M. R. S. Borges, and J. A. Pino, "Acquiring knowledge on business processes from stakeholders' stories," Advanced Engineering Informatics, 2009.

[28] A. N. Ubon and C. Kimble, Knowledge management in online distance education, 2002, Citeseer.

[29] J. Paay et al., "Engineering the social: The role of shared artifacts," International Journal of Human-Computer Studies, 2009, vol. 67, no 5, pp. 437-454

[30] K. Kreijns, P. A. Kirschner, and W. Jochems, "Identifying the pitfalls for social interaction in computer-supported collaborative learning environments: a review of the research," Computers in Human Behavior, 2003, vol. 19, no. 3, pp. 335-353

[31] H. J. So and T. A. Brush, "Student perceptions of collaborative learning, social presence and satisfaction in a blended learning environment: Relationships and critical factors," Computers \& Education, 2008, vol. 51, pp. 318-336.

[32] H. J. So and T. A. Brush, "Student perceptions of collaborative learning, social presence and satisfaction in a blended learning environment: Relationships and critical factors," Computers \& Education, 2008, vol. 51, no. 1, pp. 318-336.

[33] F. Biocca and C. Harms, "Defining and measuring social presence: Contribution to the networked minds theory and measure," in Proceedings of PRESENCE, 2002.

[34] J. B. Walther, "Interpersonal effects in computer-mediated interaction: A relational perspective," Communication Research, 1992, vol. 19, no. 1, pp. 52.

[35] C. Heeter, "Being there: the subjective experience of presence," Teleoper. Virtual Environ., 1992, vol. 1, no. 2, pp. 262-271

[36] J. W. Short, E. Williams, and B. Christie, The social psychology of telecommunications, 1976, London: Wiley.

[37] D. Gefen, E. Karahanna, and D. W. Straub, "Trust and TAM in online shopping: An integrated model," Mis Quarterly, 2003, pp. 51-90.

[38] K. Swan and L. F. Shih, "On the nature and development of social presence in online course discussions," Journal of Asynchronous learning networks, 2005, vol. 9, no. 3, pp. 115-136.

[39] N. Elmarzouqi, E. Garcia, and J. C. Lapayre, CSCW from Coordination to Collaboration, 2008, Springer.

[40] D. Helic, H. Krottmaier, and N. Scerbakov, "Enabling Project-Based Learning in WBT Systems," International Journal on E-Learning (IJEL) 2005, vol. 4, no. 4, pp. 445-461.

[41] C. H. Tu, "On-line learning migration: from social learning theory to social presence theory in a CMC environment," Journal of Network and Computer Applications, 2000, vol. 23, no. 1, pp. 27-37. 


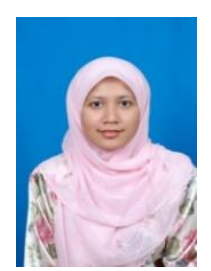

Noorihan Abdul Rahman was born in Kelantan Malaysia in year 1978. She was graduated from University of Sydney, Australia in Master of Information Technology majoring in Software Engineering and from Universiti Teknologi MARA Malaysia for her bachelor degree in Information Technology and is a lecturer of Universiti Teknologi MARA Kelantan, Malaysia. Currently, she is pursuing her $\mathrm{PhD}$ degree in Computer Science majoring in Software Engineering at the Advanced Informatics School, Universiti Teknologi Malaysia International Campus, Kuala Lumpur, Malaysia. She is doing her doctora dissertation on requirements elicitation approach for non-technical requirements which support social presence in CSCW domain. The research will include a new approach in requirements elicitation process to support social presence element in virtual communication in E-learning. She has produced conference papers related to requirements engineering, Elearning, user collaboration and other related issues with her research topic.

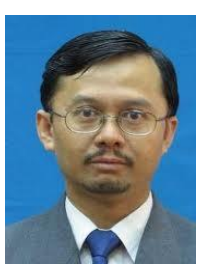

Shamsul Sahibuddin was born in Johor, Malaysia in year 1965. He was graduated from Aston University, United Kingdom for his PhD in Computer Science, his master degree in Computer Science in Central Michigan University, USA and his bachelor degree in Computer Science in Western Michigan University,

USA. Currently, he is a professor at the Advanced Informatics School, Universiti Teknologi Malaysia International Campus, Kuala Lumpur, Malaysia. He is also the Dean of Advanced Informatics School. His has produced various publications including journals, papers, monographs, teaching modules and other form of publications. He also joined as a committee member for many conferences and professional membership such as Association of Computing Machinery, ACM SIGGROUP and ACM SIGSOFT to name a few. His research interests are not limited to software engineering, groupware application and software process improvement. 